\title{
Analysis of the Safety and Pregnant Outcomes of Fertility-Sparing Surgery in Ovarian Malignant Sex Cord-Stromal Tumors: A Multicenter Retrospective Study
}

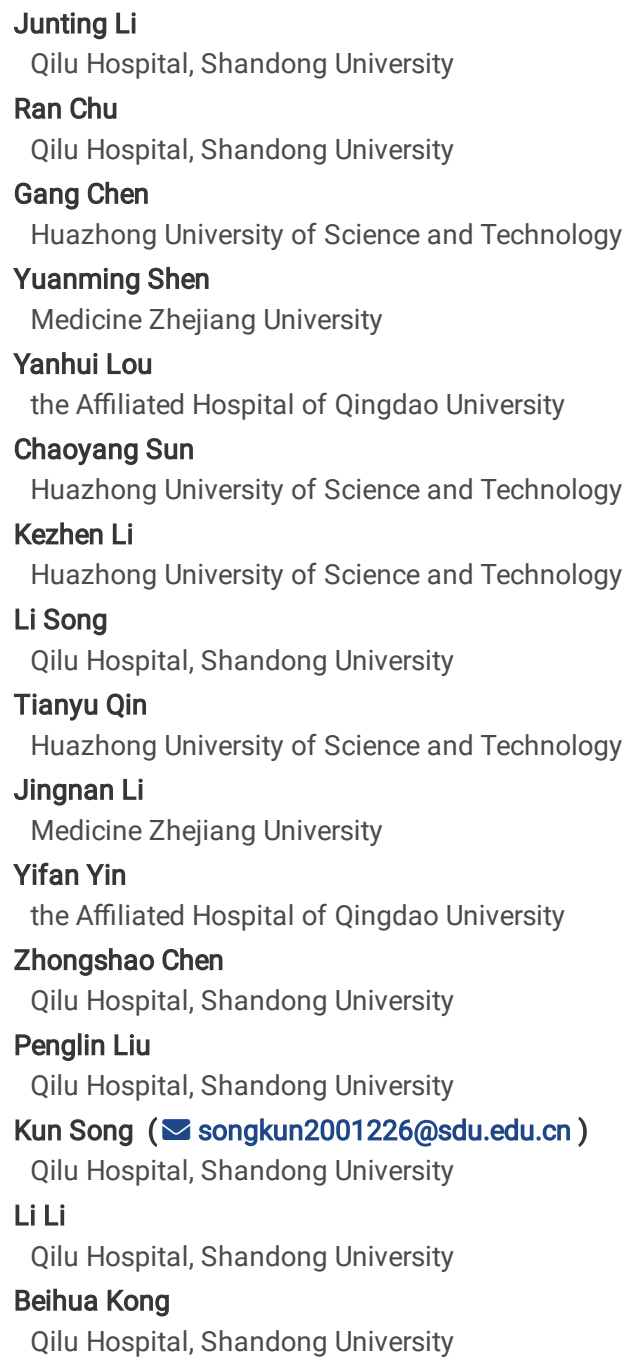

\section{Research Article}

Keywords: ovarian sex cord-stromal tumors, fertility-sparing surgery, Inverse Probability of Treatment Weighting, pregnant outcomes

Posted Date: December 13th, 2021

DOI: https://doi.org/10.21203/rs.3.rs-1155769/v1

License: (c) (1) This work is licensed under a Creative Commons Attribution 4.0 International License. Read Full License 


\section{Abstract}

Background: To assess the difference in survival between fertility-sparing surgery (FSS) and radical surgery (RS) and explore pregnant outcomes after FSS in stage I malignant sex cord-stromal tumors (MSCSTs).

Methods: We performed a multicenter retrospective cohort study on patients who were diagnosed with stage IA or IC MSCSTs. Inverse Probability of Treatment Weighting was performed between the FSS and RS groups. The Chi-square test and Kaplan-Meier method were used to compare the categorical variables and disease-free survival (DFS). The binary logistic regression analysis and Cox proportional hazards regression analysis were used to identify high-risk factors related to DFS and pregnancy.

Results: A total of 107 patients were included, of whom 54 (50.5\%) women underwent FSS, and 53 (49.5\%) women underwent RS. After IPTW, 208 patients were obtained, and all of the covariates were well balanced. After a median follow-up time of 50 months (range 7-156 months), there was no significant difference of DFS between the two groups in both unweighted cohort $(P=0.969)$ or weighted cohort $(P=0.792)$. In the weighted cohort, stage IC $(P=0.014)$, tumor diameter $>8 \mathrm{~cm}(P=0.003)$, incomplete staging surgery $(P=0.003)$ and no adjuvant chemotherapy $(P<0.001)$ were 4 high-risk factors associated with a shorter DFS. Among 14 patients who had pregnancy desire, 11 (78.6\%) women conceived successfully, and the live birth rate was $76.9 \%$. In univariate analysis, only adjuvant chemotherapy $(P=0.009)$ was associated with infertility.

Conclusions: On the premise of complete staging surgery, FSS is safe and feasible in stage IA and IC MSCSTs with satisfactory reproductive outcomes.

\section{Background}

Ovarian sex cord-stromal tumors, originated from sex cord and stromal cells of the gonads, are a type of rare non-epithelial ovarian tumors [1]. According to the World Health Organization (WHO) classification of female genital tumors in $5^{\text {th }}$ edition, OSCSTs are divided into pure stromal tumors, pure sex cord tumors and mixed sex cord-stromal tumors, which are a group of heterogeneous tumors with different clinicopathological features and biological behaviors [1, 2]. Among them, ovarian granulosa cell tumors (OGCTs), poorly differentiated Sertoli-Leydig cell tumors (SLCTs) belong to malignant sex cord-stromal tumors (MSCSTs), accounting for about $3 \%-5 \%$ of all ovarian cancers and usually occur in adolescents and young adults [1, 3, 4, 5].

Clinically, the signs and symptoms of MSCSTs present as a pelvic mass and/or hormonal manifestations, including menstrual changes, hirsutism and so on [6]. Sixty to ninety-five percent of MSCSTs are diagnosed at stage I, with a five-year disease-specific survival rate of 98\% [7]. According to the National Comprehensive Cancer Network, European Society for Medical Oncology and European Society of Gynaecological Oncology guidelines, complete staging surgery is the primary foundation treatment of MSCSTs, including hysterectomy and bilateral salpingo-oophorectomy, infracolic omentectomy, biopsy of the diaphragmatic peritoneum, paracolic gutters, pelvic peritoneum and peritoneal washings, lymphadenectomy is only performed when lymph node metastasis is suspected $[4,5,8]$. Especially, for reproductive-aged patients with fertility needs, if the tumor is confined to one ovary, fertility-sparing surgery (FSS) is available $[4,5,8]$. Therefore, gynecological oncologists also should pay attention to the prognosis and pregnant outcomes of MSCSTs patients receiving FSS treatment. However, due to its rarity, only a few studies discussed FSS, and most of them only assessed single histological subtypes.

The aim of the present study is to conduct a multicenter retrospective study, and explore the safety of FSS in MSCSTs patients. Our results could provide a more individualized reference for the chose of surgical plan in clinical practice of MSCSTs.

\section{Methods}

\section{Study participants}

This is a multicenter and retrospective cohort study from Qilu Hospital of Shandong University, Tongji Hospital of Huazhong University of Science and Technology, Women's Hospital School of Medicine Zhejiang University and the Affiliated Hospital of Qingdao University. Following the approval of The Ethical Committee in Qilu Hospital of Shandong University (2020089), we collected clinical and pathological characteristics of patients who were diagnosed with MSCSTs and had been treated with surgery in the four above hospitals between January 2010 and January 2020. The characteristics were collected from medical records, including age, histologic classification, tumor diameter, the level of carbohydrate antigen 125 (CA-125), surgical approach, surgery type, and adjuvant chemotherapy. The tumor stage refers to the International Federation of Gynecology and Obstetrics (FIGO) staging system (version 2014) [9].

Patients who met the following criteria were included in this study: (I) age <50 years, (II) premenopausal status, (III) stage IA or IC, (IV) diagnosed with MSCSTs by pathology. Patients merged other malignant tumors, tumor invasion of bilateral ovaries or incomplete medical records were excluded. Follow-up information was gained from The Hospital Follow-Up Center and telephone to patients or their families.

Finally, a total of 107 patients were included for further analysis. Patients were divided into FSS and radical surgery (RS) groups. FSS includes cystectomy, unilateral salpingo-oophorectomy (USO) and bilateral salpingo-oophorectomy (BSO). RS means hysterectomy and bilateral salping-ooophorectomy. Recurrence was evaluated by imaging examination (abdomen-pelvic ultrasound, computed tomography scan or magnetic resonance imaging), serum tumor markers and clinical presentation. Disease-free survival (DFS) was defined as months from initial surgery to recurrence time.

\section{Statistical analysis}

The Chi-square test was used to compare categorical variables between the two groups. $P<0.05$ was considered statistically significant. Then in order to minimize the impact of potential confounders on surgery selection bias, we used Inverse Probability of Treatment Weighting (IPTW) to construct a weighted cohort [10]. Bivariate logistics regression analysis was used to calculate every patient's propensity score (PS), and then we assigned a weight of $1 \div$ (PS) to the 
patients undergoing FSS and a weight of $1 \div(1-P S)$ to the patients with RS. Then all patients were weighted by the obtained weighted value to get a weighted cohort. There is no statistical difference in the characteristics of the two groups in the weighted cohort.

Combined with the log-rank test, we compared Kaplan-Meier curves of DFS between FSS and RS groups in the before and after weighted cohorts. We used univariate Cox regression analysis to perform univariate analysis of DFS, variables with a $P<0.05$ were selected for subsequent multivariate Cox regression analysis to determine independent high-risk factors. The results were described as the hazard ratio (HR), 95\% confidence interval (Cl) and $P$-value. Binary logistic regression analysis was used to perform univariate analysis of pregnancy after FSS, the results were described as the odds ratio (OR), $95 \% \mathrm{Cl}$ and $P$ value.

Chi-square test, IPTW calculation, Cox regression and Kaplan-Meier analysis were all conducted with IBM SPSS statistics (version 25.0), binary logistic regression analysis were performed with $\mathrm{R}$ software (version 4.0.4).

\section{Results}

\section{Study population}

One hundred and seven patients were included in this study, with 54 patients undergoing FSS and 53 with RS. The research flowchart is shown in Figure. 1. The median age of patients was 26 years (range: 3-47 years) and 43 years (range: 26-49 years) in the two groups, respectively. Table 1 summarizes the characteristics of patients before and after IPTW. Patients with RS were more likely to underwent complete staging surgery ( $P=0.008)$. There were no significant differences in FIGO stage, histologic classification of the tumor, tumor diameter, surgical approach, CA-125 level and adjuvant chemotherapy between the two groups. After IPTW, all of the covariates were well balanced, and there was no statistical difference in characteristics between the two groups $(P>0.05)$. In the weighted cohort, of the 208 patients, there were 107 patients in the FSS group and 101 patients in the RS group.

Table 1 Characteristics of patients in the before and after IPTW cohorts

\begin{tabular}{|c|c|c|c|c|c|c|c|c|}
\hline & Before IPT & & & & After IPTW & & & \\
\hline Characteristics & $\begin{array}{l}\text { Total } \\
(n=107)\end{array}$ & $\begin{array}{l}\text { FSS } \\
(n=54)\end{array}$ & $\begin{array}{l}\text { RS } \\
(n=53)\end{array}$ & $P$ value & $\begin{array}{l}\text { Total } \\
(n=208)\end{array}$ & $\begin{array}{l}\text { FSS } \\
(n=107)\end{array}$ & $\begin{array}{l}\text { RS } \\
(n=101)\end{array}$ & $P$ value \\
\hline FIGO stage & & & & 0.775 & & & & 0.582 \\
\hline IA & $56(52.3)$ & $29(27.1)$ & $27(25.2)$ & & $103(49.5)$ & $51(24.5)$ & $52(25.0)$ & \\
\hline IC & $51(47.7)$ & $25(23.4)$ & $26(24.3)$ & & $105(50.5)$ & $56(26.9)$ & $49(23.6)$ & \\
\hline Histologic classification & & & & 0.134 & & & & 0.928 \\
\hline OGCTs & $95(88.8)$ & $45(42.1)$ & $50(46.7)$ & & $187(89.9)$ & $96(46.2)$ & $91(43.8)$ & \\
\hline SLCTs & $12(11.2)$ & $9(8.4)$ & $3(2.8)$ & & $21(10.1)$ & $11(5.3)$ & $10(4.8)$ & \\
\hline Surgical approach & & & & 0.940 & & & & 0.932 \\
\hline Laparotomy & $40(37.4)$ & $20(18.7)$ & $20(18.7)$ & & $83(39.9)$ & $43(20.7)$ & 40 (19.2) & \\
\hline Laparoscopy & $67(62.6)$ & $34(31.8)$ & $33(30.8)$ & & $125(60.1)$ & $64(30.8)$ & $61(29.3)$ & \\
\hline Tumor diameter (cm) & & & & 0.386 & & & & 0.791 \\
\hline$\leq 8$ & $55(51.4)$ & $30(28.0)$ & $25(23.4)$ & & $101(48.6)$ & $51(24.5)$ & $50(24.0)$ & \\
\hline$>8$ & $52(48.6)$ & $24(22.4)$ & $28(26.2)$ & & $107(51.4)$ & $56(26.9)$ & $51(24.5)$ & \\
\hline $\mathrm{CA}-125(\mathrm{U} / \mathrm{ml})$ & & & & 0.260 & & & & 0.546 \\
\hline$<35$ & $84(78.5)$ & $40(37.4)$ & $44(41.1)$ & & $161(77.4)$ & $81(38.9)$ & $80(38.5)$ & \\
\hline$\geq 35$ & $23(21.5)$ & $14(13.1)$ & $9(8.4)$ & & $47(22.6)$ & $26(12.5)$ & $21(10.1)$ & \\
\hline Staging surgery & & & & 0.008 & & & & 0.910 \\
\hline Yes & $81(75.7)$ & $35(32.7)$ & $46(43.0)$ & & $162(77.9)$ & $83(39.9)$ & $79(38.0)$ & \\
\hline No & $26(24.3)$ & $19(17.8)$ & $7(6.5)$ & & $46(22.1)$ & $24(11.5)$ & $22(10.6)$ & \\
\hline Adjuvant chemotherapy & & & & 0.945 & & & & 0.998 \\
\hline Yes & $71(66.4)$ & $36(33.6)$ & $35(32.7)$ & & $138(66.3)$ & $71(34.1)$ & $67(32.2)$ & \\
\hline No & $36(33.6)$ & $18(16.8)$ & $18(16.8)$ & & 70 (33.7) & $36(34.1)$ & $34(16.3)$ & \\
\hline
\end{tabular}

Values are present as $\mathrm{n}(\%)$ or median (range) 


\section{Survival outcomes}

The Median follow-up time was 50 months (range: 7-156 months). As a result, there was no statistical difference of DFS between FSS and RS groups both in the unweighted cohort $(P=0.969)$ and weighted cohort $(P=0.792)$ (Figure. 2). Table 2 lists the information of relapsed and dead patients. Ninety percent of relapsed patients were in stage IC, $80 \%$ did not undergo surgical staging, and $70 \%$ did not received adjuvant chemotherapy. Women were all treated with surgery after recurrence. Two women died, the 20-year old patient died of lung cancer 22 months after recurrence, the other 40 -year women died after 12 months with a 2 cycles adjuvant chemotherapy.

Table 2 Clinicopathological details of relapsing and dead patients in stage I patients

\begin{tabular}{|c|c|c|c|c|c|c|c|c|c|c|c|c|}
\hline case & Age & $\begin{array}{l}\text { FIGO } \\
\text { stage }\end{array}$ & $\begin{array}{l}\text { Histologic } \\
\text { classification }\end{array}$ & $\begin{array}{l}\text { Surgery } \\
\text { type }\end{array}$ & $\begin{array}{l}\text { Staging } \\
\text { surgery }\end{array}$ & $\begin{array}{l}\text { Adjuvant } \\
\text { chemotherapy }\end{array}$ & recurrence & $\begin{array}{l}\text { Recurrence } \\
\text { site }\end{array}$ & $\begin{array}{l}\text { Treatment } \\
\text { after } \\
\text { recurrence }\end{array}$ & $\begin{array}{l}\text { DFS } \\
\text { (months) }\end{array}$ & Death & $\begin{array}{l}\text { OS } \\
\text { (months) }\end{array}$ \\
\hline 1 & 16 & IC & OGCTs & USO & No & $\mathrm{TC}^{\star} 6$ & Yes & Abdomen & $\begin{array}{l}\text { Surgery + } \\
A C\end{array}$ & 38 & No & 58 \\
\hline 2 & 20 & IC & SLCTS & USO & No & No & Yes & Pelvis & Surgery & 14 & Yes & 36 \\
\hline 3 & 33 & IC & OGCTs & RS & No & No & Yes & $\begin{array}{l}\text { Pelvis + } \\
\text { abdomen }\end{array}$ & $\begin{array}{l}\text { Surgery + } \\
\text { AC }\end{array}$ & 58 & No & 88 \\
\hline 4 & 35 & IC & OGCTs & USO & No & No & Yes & $\begin{array}{l}\text { Contralateral } \\
\text { ovary }\end{array}$ & $\begin{array}{l}\text { Surgery + } \\
\text { AC }\end{array}$ & 108 & No & 156 \\
\hline 5 & 36 & $\mathrm{IA}$ & OGCTs & $\mathrm{RS}$ & Yes & $\mathrm{BEP} * 3$ & Yes & Pelvis & $\begin{array}{l}\text { Surgery + } \\
\text { AC }\end{array}$ & 35 & No & 92 \\
\hline 6 & 38 & IC & OGCTs & USO & No & No & Yes & Pelvis & $\begin{array}{l}\text { Surgery + } \\
A C\end{array}$ & 5 & No & 111 \\
\hline 7 & 38 & IC & OGCTs & $\mathrm{RS}$ & No & No & Yes & Pelvis & Surgery & 65 & No & 88 \\
\hline 8 & 40 & IC & SLCTs & $\mathrm{RS}$ & Yes & $B E P \star 2$ & No & - & - & 12 & Yes & 12 \\
\hline 9 & 42 & IC & OGCTs & $\mathrm{RS}$ & Yes & $\mathrm{BEP} * 6$ & Yes & Pelvis & Surgery & 57 & No & 82 \\
\hline 10 & 43 & IC & OGCTs & $\mathrm{RS}$ & No & No & Yes & Pelvis & $\begin{array}{l}\text { Surgery + } \\
\text { AC }\end{array}$ & 36 & No & 52 \\
\hline 11 & 48 & IC & SLCTS & $\mathrm{RS}$ & No & No & Yes & $\begin{array}{l}\text { Pelvis + } \\
\text { abdomen }\end{array}$ & $\begin{array}{l}\text { Surgery + } \\
\mathrm{AC}\end{array}$ & 35 & No & 50 \\
\hline
\end{tabular}

FIGO=International Federation of Gynecology and Obstetrics, DFS=disease-free survival, OS=overall survival, OGCTs=ovarian granular cell tumors, SLCTs=Sertoli-Leydig cell tumors, RS=radical surgery, USO=unilateral salpingo-oophorectomy, TC=paclitaxel/carboplatin, BEP=bleomycin/etoposide/cisplatin

\section{High-risk factors of DFS}

We further analyzed high-risk factors for DFS, and the results are shown in Table 3. In the univariate analysis, FIGO stage ( $P=0.002)$, surgical approach $(P=0.015)$, tumor diameter $(P=0.001)$, CA-125 level $(P=0.006)$, complete staging surgery $(P<0.001)$ and adjuvant chemotherapy $(P<0.001)$ were associated with DFS, while surgery type ( $P=0.796)$, age $(P=0.744)$, histologic classification $(P=0.073)$ had no effect on DFS. Furthermore, in multivariate analysis, FIGO stage (HR=6.50, 95\% Cl: 1.45-29.10, $P=0.014)$, tumor diameter (HR=16.80, 95\% Cl: 2.67-105.53, $P=0.003)$, complete staging surgery (HR=4.67, 95\% Cl: 1.6613.08, $P=0.003)$, adjuvant chemotherapy ( $\mathrm{HR}=12.98,95 \% \mathrm{Cl}: 4.16-40.46, P<0.001)$ were 4 independent high-risk factors of $\mathrm{DFS}$.

\section{Pregnant outcomes}

Detailed pregnant outcomes are shown in Table 4. Of the 53 patients with FSS, 14 had pregnancy desire in the follow-up period and 78.6\% (11/14) successfully achieved 15 singleton pregnancies, including 10 term births, 3 spontaneous abortions and 2 at pregnancy status. The live birh rate was $76.9 \%$. None of the 14 patients experienced recurrence during the follow-up period. Among three patients who failed pregnancy, one of them was 25 -year-old with polycystic ovary syndrome and underwent 6 cycles of adjuvant chemotherapy (bleomycin, etoposide and cisplatin regimen), another patient was 30 years and underwent 4 cycles of adjuvant chemotherapy, and the last 42-year-old woman underwent hysterectomy because of endometrial complex hyperplasia 84 months after FSS.

\section{High-risk factors of pregnancy}

When factors influenced pregnancy were analyzed, in univariate analysis, only adjuvant chemotherapy led to poor pregnant outcomes $(P=0.009)$, and the results are shown in Figure. 3. No differences in pregnancy were noted on age $(P=0.147)$, FIGO stage $(P=0.969)$, histologic classification $(P=0.669)$, surgical approach ( $P=0.342)$, surgical procedure $(P=0.480)$, tumor diameter $(P=0.342)$, CA-125 level $(P=0.568)$ or complete staging surgery $(P=0.382)$.

Table 3 Univariate and multivariate COX regression analysis of risk factors related to DFS 
Before IPTW

\begin{tabular}{|c|c|c|c|c|c|c|c|c|}
\hline \multirow[t]{2}{*}{ Characteristics } & \multicolumn{2}{|l|}{ Univariate } & \multicolumn{2}{|l|}{ Multivariate } & \multicolumn{2}{|l|}{ Univariate } & \multicolumn{2}{|l|}{ Multivariate } \\
\hline & $\mathrm{HR}(95 \% \mathrm{Cl})$ & $P$ value & $\mathrm{HR}(95 \% \mathrm{Cl})$ & $P$ value & $\mathrm{HR}(95 \% \mathrm{Cl})$ & $P$ value & $\mathrm{HR}(95 \% \mathrm{Cl})$ & $P$ value \\
\hline Surgery type & & 0.969 & & & & 0.796 & & \\
\hline RS & Reference & & & & Reference & & & \\
\hline FSS & $1.03(0.30-3.55)$ & & & & $0.90(0.41-1.98)$ & & & \\
\hline Age (y) & $0.99(0.94-1.05)$ & 0.860 & & & $1.01(0.97-1.04)$ & 0.744 & & \\
\hline FIGO stage & & 0.037 & & 0.049 & & 0.002 & & 0.014 \\
\hline IA & Reference & & Reference & & Reference & & Reference & \\
\hline IC & $\begin{array}{l}9.04(1.15- \\
71.43)\end{array}$ & & $9.31(1.01-85.60)$ & & $9.99(2.36-42.41)$ & & $6.50(1.45-29.10)$ & \\
\hline $\begin{array}{l}\text { Histologic } \\
\text { classification }\end{array}$ & & 0.383 & & & & 0.073 & & \\
\hline OGCTs & Reference & & & & Reference & & & \\
\hline SLCTs & $2.01(0.42-9.70)$ & & & & $2.48(0.92-6.69)$ & & & \\
\hline Surgical approach & & 0.078 & & & & 0.015 & & \\
\hline Laparotomy & Reference & & & & Reference & & & \\
\hline Laparoscopy & $0.30(0.08-1.15)$ & & & & $0.35(0.15-0.81)$ & & & \\
\hline Tumor diameter (cm) & & 0.031 & & 0.038 & & 0.001 & & 0.003 \\
\hline$\leq 8$ & Reference & & Reference & & Reference & & Reference & \\
\hline$>8$ & $\begin{array}{l}9.74(1.23- \\
76.96)\end{array}$ & & $\begin{array}{l}13.00(1.15- \\
149.60)\end{array}$ & & $\begin{array}{l}11.28(2.66- \\
47.87)\end{array}$ & & $\begin{array}{l}16.80(2.67- \\
105.53)\end{array}$ & \\
\hline $\mathrm{CA}-125(\mathrm{U} / \mathrm{ml})$ & & 0.026 & & & & 0.006 & & \\
\hline$<35$ & Reference & & & & Reference & & & \\
\hline$\geq 35$ & $\begin{array}{l}4.46(1.19- \\
16.66)\end{array}$ & & & & $3.14(1.38-7.14)$ & & & \\
\hline Staging surgery & & 0.005 & & & & $<0.001$ & & 0.003 \\
\hline Yes & Reference & & & & Reference & & Reference & \\
\hline No & $\begin{array}{l}7.03(1.82- \\
27.22)\end{array}$ & & & & $8.26(3.56-19.18)$ & & $4.67(1.66-13.08)$ & \\
\hline $\begin{array}{l}\text { Adjuvant } \\
\text { chemotherapy }\end{array}$ & & 0.014 & & 0.006 & & $<0.001$ & & $<0.001$ \\
\hline Yes & Reference & & Reference & & Reference & & Reference & \\
\hline No & $\begin{array}{l}5.52(1.42- \\
21.48)\end{array}$ & & $8.22(1.84-36.69)$ & & $\begin{array}{l}12.82(4.40- \\
37.40)\end{array}$ & & $12.98(4.16-40.46)$ & \\
\hline
\end{tabular}

DFS=disease-free survival, IPTW=Inverse Probability of Treatment Weighting, HR=hazard ratio, Cl=confidence interval, RS=radical surgery, FSS=fertility-sparing surgery, FIGO=International Federation of Gynecology and Obstetrics, OGCTs=ovarian granulosa cell tumors, SLCTs=Sertoli-Leydig cell tumors, CA$125=$ carbohydrate antigen 125

Table 4 Characteristics of patients who had desire of conception 


\begin{tabular}{|c|c|c|c|c|c|c|c|c|c|c|}
\hline Case & Age & $\begin{array}{l}\text { FIGO } \\
\text { stage }\end{array}$ & $\begin{array}{l}\text { Histologic } \\
\text { classification }\end{array}$ & Surgery & $\begin{array}{l}\text { Adjuvant } \\
\text { chemotherapy }\end{array}$ & Pregnancy & $\begin{array}{l}\text { Numbers of } \\
\text { pregnancies }\end{array}$ & $\begin{array}{l}\text { Pregnancy } \\
\text { outcome }\end{array}$ & Recurrence & $\begin{array}{l}\text { DFS } \\
\text { (months) }\end{array}$ \\
\hline 1 & 21 & $\mathrm{IA}$ & OGCTs & $\begin{array}{l}\text { USO with } \\
\text { staging }\end{array}$ & $\mathrm{BEP} * 3$ & Yes & 2 & Both live birth & No & 115 \\
\hline 2 & 25 & $\mathrm{IA}$ & OGCTs & USO & $\mathrm{BEP} * 6$ & No & 0 & None & No & 84 \\
\hline 3 & 25 & IC & OGCTs & $\begin{array}{l}\text { USO with } \\
\text { staging }\end{array}$ & $\mathrm{BEP} * 2$ & Yes & 1 & During pregnancy & No & 47 \\
\hline 4 & 28 & $\mathrm{IA}$ & OGCTs & $\begin{array}{l}\text { USO with } \\
\text { staging }\end{array}$ & No & Yes & 2 & $\begin{array}{l}\text { Spontaneous } \\
\text { abortion, live birth }\end{array}$ & No & 67 \\
\hline 5 & 28 & $\mathrm{IA}$ & OGCTs & Cystectomy & No & Yes & 1 & Live birth & No & 34 \\
\hline 6 & 29 & $\mathrm{IA}$ & OGCTs & USO & No & Yes & 1 & Live birth & No & 90 \\
\hline 7 & 30 & $\mathrm{IA}$ & OGCTs & $\begin{array}{l}\text { USO with } \\
\text { staging }\end{array}$ & $\mathrm{BEP} * 4$ & No & 0 & None & No & 42 \\
\hline 8 & 31 & $\mathrm{IA}$ & SLCTS & $\begin{array}{l}\text { USO with } \\
\text { staging }\end{array}$ & $\mathrm{TP} * 1$ & Yes & 1 & Live birth & No & 74 \\
\hline 9 & 33 & $\mathrm{IA}$ & OGCTs & $\begin{array}{l}\text { USO with } \\
\text { staging }\end{array}$ & $\mathrm{BEP} * 3$ & Yes & 2 & $\begin{array}{l}\text { Spontaneous } \\
\text { abortion, live birth }\end{array}$ & No & 43 \\
\hline 10 & 33 & IC & SLCTS & Cystectomy & $\mathrm{BEP} * 4$ & Yes & 2 & Both live birth & No & 63 \\
\hline 11 & 35 & IC & OGCTs & $\begin{array}{l}\text { USO with } \\
\text { staging }\end{array}$ & $\mathrm{BEP} * 4$ & Yes & 1 & $\begin{array}{l}\text { Spontaneous } \\
\text { abortion }\end{array}$ & No & 125 \\
\hline 12 & 36 & IC & OGCTs & $\begin{array}{l}\text { USO with } \\
\text { staging }\end{array}$ & No & Yes & 1 & During pregnancy & No & 7 \\
\hline 13 & 37 & IA & OGCTs & USO & No & Yes & 1 & Live birth & No & 30 \\
\hline 14 & 42 & IA & SLCTS & USO & No & No & 0 & None & No & 84 \\
\hline
\end{tabular}

FSS=fertility-sparing surgery, FIGO=International Federation of Gynecology and Obstetrics, OGCTs=ovarian granular cell tumors, SLCTs=Sertoli-Leydig cell tumors, USO=unilateral salpingo-oophorectomy, BEP=bleomycin/etoposide/cisplatin, TP=paclitaxel/cisplatin, DFS=disease-free survival

\section{Discussion}

Based on the younger age of MSCSTs, fertility-sparing surgery is becoming increasingly important [11]. Our multicenter study suggests that FSS did not result in a shorter DFS compared with RS for stage I MSCSTs, and the pregnant outcomes are hopeful. Besides, we observed that adjuvant chemotherapy was associated with a higher risk of infertility. To our knowledge, this is the first study to explore the influence of single factor of FSS on the prognosis of MSCSTs. Through propensity-score weighting, it balanced the bias of other clinical-pathological factors and individual selection differences.

Previous retrospective studies have indicated that apart from a worse cancer-specific survival (4.3\% vs $11.8 \%$ ), there is no inferiority of DFS and OS in women who underwent FSS, compared those with RS [12-15]. However, there is a serious limitation that selection bias, the possibility of treatment heterogeneity and other clinicopathological features affecting oncologic outcomes were inconsistent. In our study, we used the original cohort and the weighted cohort to compare the survival difference of FSS and RS. By survival analysis and multivariate Cox regression analysis, both cohorts showed no difference in DFS between the two treatment groups. In addition, we discussed the high-risk factors of DFS in stage I MSCSTs. We got that stage IA, complete staging surgery, tumor diameter $<8 \mathrm{~cm}$ and adjuvant chemotherapy were associated with a longer DFS. The tumor stage has proven to be the most important prognostic factor of MSCSTs, the 5-year disease-specific survival rate of stage I MSCSTs was 98\%, and the survival rate of stage II-IV was lower than $80 \%$ [7, 16, 17]. Complete staging surgery was also an independent predictive factor of DFS. In an analysis of 2680 OGCTs from the National Cancer Database, the incomplete surgical stage was obviously associated with an increased risk of death (five-year survival: $90.2 \%$ and $84.2 \%$ ) [18]. Therefore, large omental biopsy, omentectomy or biopsy of the peritoneum is essential for patients with 15 to 25 years $[4,5,8]$. However, the prognostic significance of adjuvant chemotherapy in MSCSTs is controversial to now. In international guidelines, platinum-based adjuvant chemotherapy or observation is recommended for stage I MSCSTs with high-risk factors (SLCTs, stage IC, tumor rupture, low differentiation, stage IC2 or IC3 Juvenile OGCTs) [4, 5, 8]. In the two larger series in the literature, Dimitrios Nasioudis et al. concluded that adjuvant chemotherapy had no significant effect on OS in stage I non-OGCTs MSCSTs [19]. In Anton Oseledchyk's article, regardless of tumor stage, adjuvant chemotherapy has nothing to do with five-year disease-specific survival in 739 OGCTs [20]. Different from earlier studies, our study showed the importance of adjuvant chemotherapy, the patients receiving adjuvant chemotherapy had a prolonged DFS. The effects of adjuvant chemotherapy on MSCSTs prognosis still need to be supported by large sample data and prospective studies.

Furthermore, we assessed pregnant outcomes after FSS and high-risk factors of pregnancy. Our data showed that the pregnancy rate was 78.6\%. Among three patients with infertility, 2 women underwent adjuvant chemotherapy, and in univariate analysis, only adjuvant chemotherapy was associate with infertility. Our previous review summarized the pregnant outcomes of related articles, with pregnancy rate of $80 \%-86 \%$ and live birth rate of $96 \%$ [ 11 ]. Chemotherapy-induced ovarian toxicity is one of the causes [21]. In O. Solheim's article, the number of cycles based on cisplatin chemotherapy is the only factor significantly associated with fertility $(\mathrm{HR}=2.9, P=0.038)$ [22]. According to the latest guidelines for MSCSTs, paclitaxel/carboplatin regimen chemotherapy is preferred, but 
the comprehensive impact of chemotherapy and its regimens on fertility and survival still needs large samples to evaluate [5]. It is important to adjuvant chemotherapy indications.

\section{Strengths and weaknesses}

There are still some limitations in this study. First, this is a retrospective study, data integrity is flawed, such as some patients have forgotten the specific time of their menstrual recovery after surgery. Second, the longest follow-up time was 156 months, during which 2 deaths were monitored, the difference in OS between the two groups could not be analyzed. Besides, of the 54 patients with FSS, only 14 women tried to get pregnant during the follow-up period, and 17 patients were younger than 20 years old, so there was a limited interpretation of pregnant outcomes and survival after pregnancy.

\section{Conclusions}

We comprehensively analyzed the safety and reproductive outcomes of FSS and risk factors of recurrence in stage I MSCSTs. In conclusion, based on complete surgical staging, FSS is favorable for stage I patients with desirable pregnant outcomes.

\section{Abbreviations}

MSCSTs: malignant sex cord-stromal tumors

OGCTs: ovarian granulosa cell tumors,

SLCTs: poorly differentiated Sertoli-Leydig cell tumors

FSS: fertility-sparing surgery

RS: radical surgery

CA-125: carbohydrate antigen 125

IPTW: Inverse Probability of Treatment Weighting

PS: propensity score

HR: hazard ratio

DFS: disease-free survival

\section{Declarations}

\section{Ethics approval and consent to participate}

The research was approved by The Ethical Committee in Qilu Hospital of Shandong University (2020089).

\section{Consent for publication}

Not applicable.

\section{Availability of data and materials}

The datasets used and/or analysed during the current study are available from the corresponding author on reasonable request.

\section{Competing interests}

The authors declare that they have no competing interests.

\section{Funding}

This work was supported by the National Key Technology R\&D Program of China (grant numbers 2019YFC1005200 and 2019YFC1005204), the Taishan Scholar Youth Project of Shandong Province (grant number tsqn201812130), and the Research Leader Studio of Jinan (grant number 2019GXRC049).

\section{Authors' contributions}

JTL, RC wrote and revised the manuscript, TYQ, JNL, YFY, ZSC and PLL collected data, GC, CYS, YHL, YMS, KZL and LS supervised and revised the article, KS $\mathrm{LL}$ and BHK determined the direction of the article and completed the review of the article.

\section{Acknowledgements}

Not applicable. 


\section{References}

1. Kurman RJ, Carcangiu ML, Harrington CS, et al. WHO Classification of Tumours of Female Reproductive Organs, 4th Edition. WHO/IARC Classification of Tumours. Vol. 6. Lyon: IARC Publications, 2014. Available from: https://www.iarc.fr/news-events/iarc-publications-whoclassification-of-tumours-offemale-reproductive-organs-fourth-edition/

2. Lim D, Oliva E. Ovarian sex cord-stromal tumours: an update in recent molecular advances. Pathology. 2018,50:178-89.

3. Gatta G, van der Zwan JM, Casali PG, Siesling S, Dei Tos AP, Kunkler I, et al. Rare cancers are not so rare: the rare cancer burden in Europe. Eur J Cancer. 2011,47:2493-511

4. Ray-Coquard I, Morice P, Lorusso D, Prat J, Oaknin A, Pautier P, et al. ESMO Guidelines Committee. Non-epithelial ovarian cancer: ESMO Clinical Practice Guidelines for diagnosis, treatment and follow-up. Ann Oncol. 2018,29:iv1-18.

5. Deborah K, Ronald D, et al. National Comprehensive Cancer Network. NCCN clinical practice guidelines in oncology: ovarian cancer, version 2.2021. Available from: https://www.nccn.org/professionals/physician_gls/pdf/ovarian.pdf. Accessed 17 August 2021

6. Schultz KA, Harris AK, Schneider DT, Young RH, Brown J, Gershenson DM, et al. Ovarian Sex Cord-Stromal Tumors. J Oncol Pract. 2016,12:940-6.

7. Torre LA, Trabert B, DeSantis CE, Miller KD, Samimi G, Runowicz CD, et al. Ovarian cancer statistics. CA Cancer J Clin. 2018,68:284-96.

8. Sessa C, Schneider DT, Planchamp F, Baust K, Braicu El, Concin N, et al. ESGO-SIOPE guidelines for the management of adolescents and young adults with non-epithelial ovarian cancers. Lancet Oncol. 2020,21:e360-8.

9. Mutch DG, Prat J. 2014 FIGO staging for ovarian, fallopian tube and peritoneal cancer. Gynecol Oncol. 2014,133:401-4.

10. Austin PC, Stuart EA. Moving towards best practice when using inverse probability of treatment weighting (IPTW) using the propensity score to estimate causal treatment effects in observational studies. Stat Med. 2015,34:3661-79.

11. Li J, Chu R, Chen Z, Meng J, Yao S, Song K, et al. Progress in the management of ovarian granulosa cell tumor: A review. Acta Obstet Gynecol Scand. 2021,100:1771-8.

12. Wang D, Cao D, Jia C, Huang H, Yang J, Wu M, et al. Analysis of oncologic and reproductive outcomes after fertility-sparing surgery in apparent stage I adult ovarian granulosa cell tumors. Gynecol Oncol. 2018,151:275-81.

13. Nasioudis D, Frey MK, Chapman-Davis E, Witkin SS, Holcomb K. Safety of Fertility-Sparing Surgery for Premenopausal Women With Sex Cord-Stromal Tumors Confined to the Ovary. Int J Gynecol Cancer. 2017,27:1826-32.

14. Zhao D, Song Y, Zhang Y, Li B. Outcomes of fertility-sparing surgery in ovarian juvenile granulosa cell tumor. Int J Gynecol Cancer. 2019,29:787-91.

15. lavazzo C, Gkegkes ID, Vrachnis N. Fertility sparing management and pregnancy in patients with granulosa cell tumour of the ovaries. J Obstet Gynaecol. 2015,35:331-5.

16. Zhang M, Cheung MK, Shin JY, Kapp DS, Husain A, Teng NN, et al. Prognostic factors responsible for survival in sex cord stromal tumors of the ovary-an analysis of 376 women. Gynecol Oncol. 2007,104:396-400.

17. Ray-Coquard I, Brown J, Harter P, Provencher DM, Fong PC, Maenpaa J, et al. Gynecologic Cancer InterGroup (GCIG) consensus review for ovarian sex cord stromal tumors. Int J Gynecol Cancer. 2014,24:S42-7.

18. Seagle BL, Ann P, Butler S, Shahabi S. Ovarian granulosa cell tumor: A National Cancer Database study. Gynecol Oncol.2017,146:285-91.

19. Nasioudis D, Orfanelli T, Frey MK, Chapman-Davis E, Caputo TA, Witkin SS, et al. Role of adjuvant chemotherapy in the management of non-granulosa cell ovarian sex cord-stromal tumors. J Gynecol Oncol. 2019,30:e19.

20. Oseledchyk A, Gennarelli RL, Leitao MM Jr, Aghajanian CA, lasonos A, Zivanovic O, et al. Adjuvant chemotherapy in patients with operable granulosa cell tumors of the ovary: a surveillance, epidemiology, and end results cohort study. Cancer Med. 2018,7:2280-7.

21. Spears N, Lopes F, Stefansdottir A, Rossi V, De Felici M, Anderson RA, et al. Ovarian damage from chemotherapy and current approaches to its protection. Hum Reprod Update. 2019,25:673-93.

22. Solheim O, Tropé CG, Rokkones E, Kærn J, Paulsen T, Salvesen HB, et al. Fertility and gonadal function after adjuvant therapy in women diagnosed with a malignant ovarian germ cell tumor (MOGCT) during the "cisplatin era". Gynecol Oncol. 2015,136:224-9.

\section{Figures}




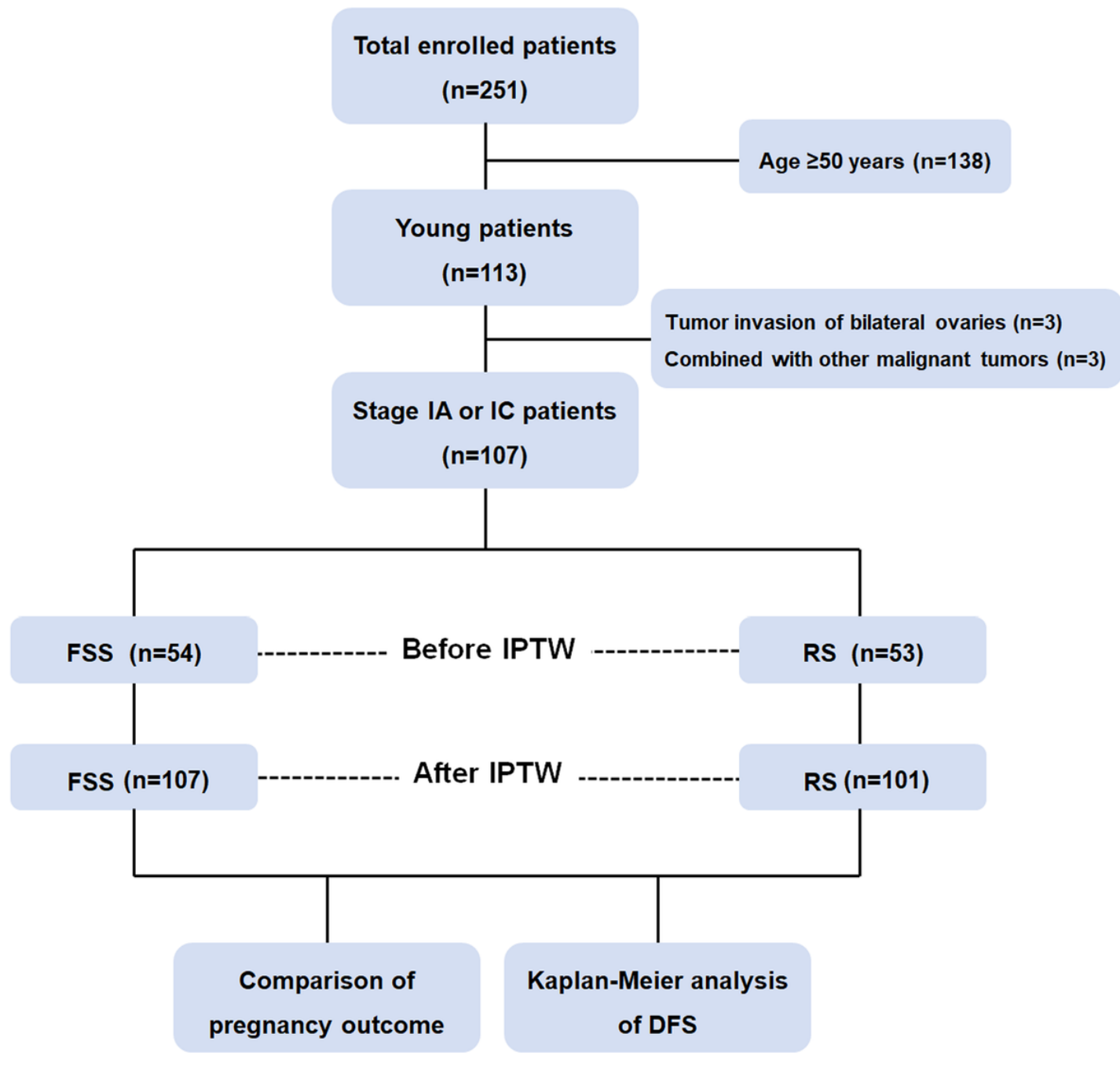

Figure 1

Flowchart of the study FSS=fertility-sparing surgery, RS=radical surgery, DFS=disease-free survival, IPTW=Inverse Probability of Treatment Weighting 

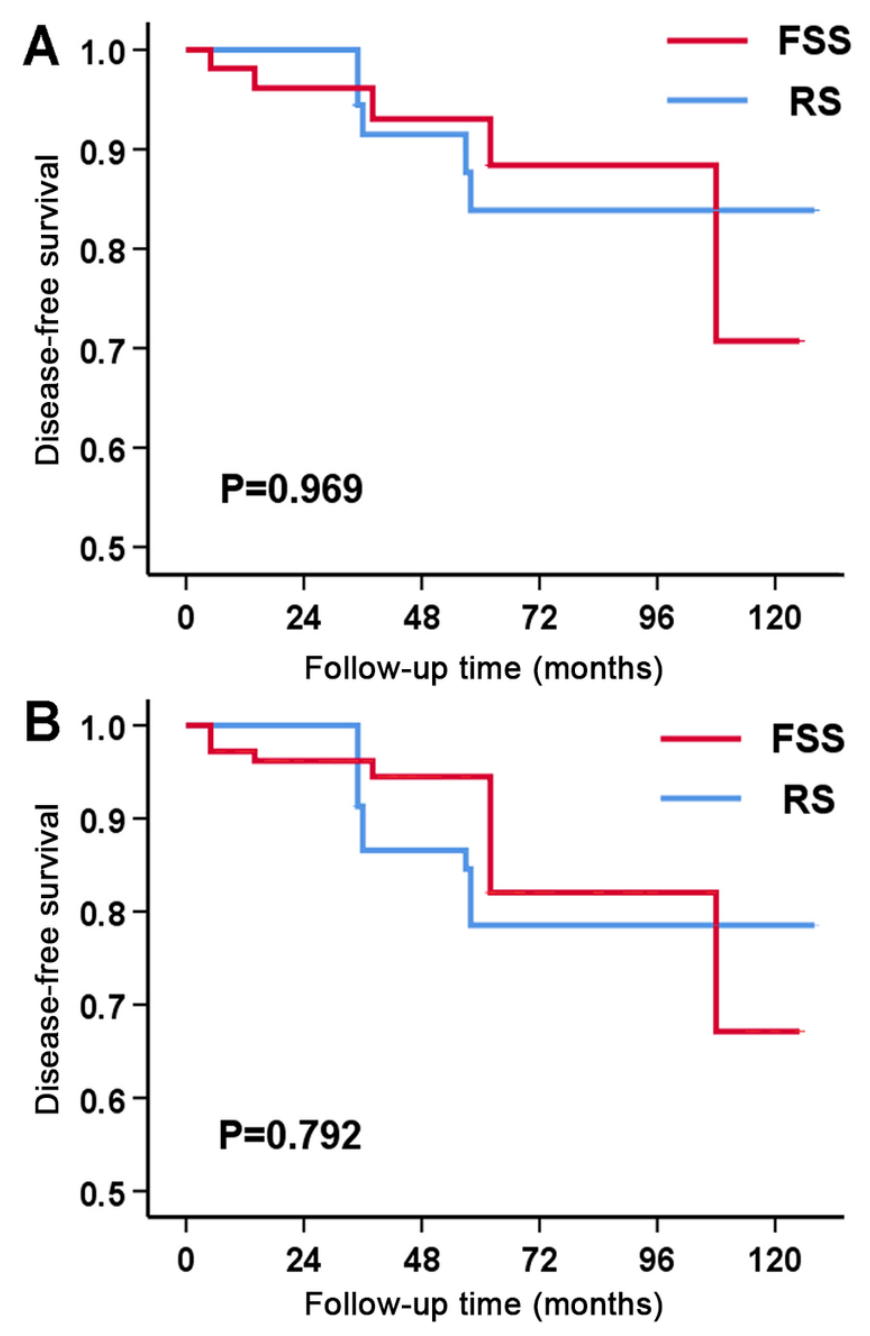

Figure 2

Survival curves of DFS before IPTW (A) and after IPTW (B) IPTW=Inverse Probability of Treatment Weighting, FSS=fertility-sparing surgery, RS=radical surgery, DFS=disease-free survival 


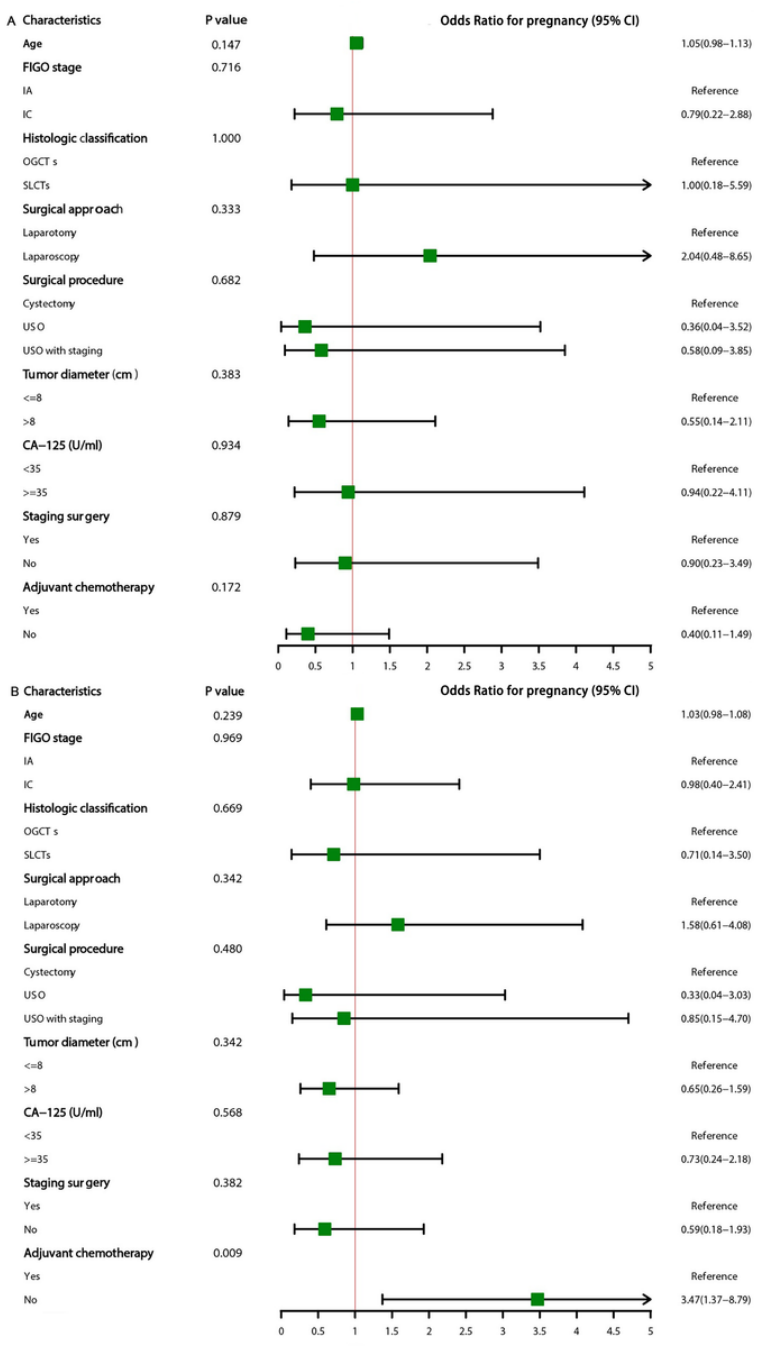

\section{Figure 3}

Univariate logistic regression analysis of pregnancy before IPTW (A) and after IPTW (B) IPTW=Inverse Probability of Treatment Weighting, FIGO=International Federation of Gynecology and Obstetrics, OGCTs=ovarian granulosa cell tumors, SLCTs=Sertoli-Leydig cell tumors, USO=unilateral salpingo-oophorectomy 